\title{
Maternal Factors and Neonatal Mortality and Morbidity Associated with Late Preterm Birth
}

\author{
Heidi K. Al-Wassia, MD \\ Department of Pediatrics, Faculty of Medicine \\ King Abdulaziz University, Jeddah, Saudi Arabia
}

\section{Correspondence}

Dr. Heidi K. Al-Wassia

P.O. Box 80215, Jeddah 21589, Saudi Arabia

e.M: halwassia@kau.edu.sa

Submission: 10 Aug. 2015

Accepted: $\quad 15$ Sep. 2015

\section{Citation}

Al-Wassia HK. Maternal factors and neonatal mortality and morbidity associated with late preterm birth. JKAU Med Sci 2015; 22 (4): 1-8. DOl: 10.4197/Med. 22.4.1

\begin{abstract}
The objective of this study is to ascertain risk factors and outcomes associated with late preterm birth. A 1:1 matched case-control study of mothers who delivered at $34^{+0}$ to $36^{+6}$ weeks gestation (cases) and at term (controls) at King Abdulaziz University Hospital, Jeddah, Saudi Arabia between June 1st, 2014 and March 30th, 2015. We enrolled 53 cases and 53 controls. Mothers of late preterm infants were older ( $p$ $=0.03)$, with higher parity $(p=0.04)$, body mass index $(p=0.01)$ and multiple pregnancies $(p=<0.001)$ compared to mothers of infants born at term. A higher proportion of hypertension and $(p=0.01)$ and premature rupture of membrane $(p=<0.001)$ preceded late preterm deliveries. Cesarean section frequency was greater in late preterm infants $(p=0.002)$. Late preterm infants were admitted to the neonatal intensive care unit more frequently than their term counterparts $(p=<$ $0.001)$, had more respiratory adverse outcomes $(p=0.006)$ and longer hospital stay $(p=0.001)$. Late preterm birth is a substantial perinatal health problem warranting a closer look at efforts to improve prenatal care strategies to reduce risk factors associated with it and prevent non-medically indicated premature birth.
\end{abstract}

\section{Keywords}

Late preterm; Risk factors; Morbidity

\section{Introduction}

he rate of late preterm delivery, described as labor occurring between $34^{+0}$ to $36^{+6}$ completed gestational weeks has risen worldwide ${ }^{[1-3]}$. Late preterm birth has a substantial impact on perinatal health because of its associated mortality ${ }^{[4,5]}$, early-life and enduring morbidities and financial implications for the health care-system ${ }^{[6-9]}$.

Controversies exist over the rate of inevitable late preterm delivery. While Holland et al. ${ }^{[10]}$ demonstrated that more than $80 \%$ of deliveries of late preterm infants were inexorable, Reddy et al. ${ }^{[1]}$ reported that $23 \%$ of late preterm births were iatrogenic. latrogenic delivery at $34^{+0}$ to $36^{+6}$ weeks is medically indicated when the risk of associated morbidity and mortality is less than that of expectant management. Moreover, obstetricians reported inconsistencies in the management of late preterm pregnancies in that $71 \%$, $69 \%$ and $33 \%$ will proceed with delivery of cases with severe preeclampsia, early rupture of membranes and placenta previa, respectively ${ }^{[12]}$.

Risk variables related to late preterm delivery reported in the literature includes very young and advanced maternal age ${ }^{[13,14]}$, assisted reproductive technology (ART) and the resultant multiple 
pregnancy ${ }^{[15,16]}$, previous preterm birth $^{[17]}$, obesity ${ }^{[18]}$, hypertension ${ }^{[13]}$, smoking ${ }^{[19]}$, positive urine and/or vaginal culture ${ }^{[13]}$ and preterm premature rupture of membrane (PROM).

The purpose of our study is to ascertain risk factors and outcomes related to late preterm birth in women who gave birth at King Abdulaziz University Hospital.

Primary Objective: To study the risk factors in the population of women giving birth at King Abdulaziz University Hospital associated with late preterm delivery.

Secondary Objectives: To establish the effect of late preterm delivery on neonatal mortality and morbidity.

\section{Materials and Methods}

\section{Study Design}

Case control study

\section{Population}

Cases were women who gave birth at King Abdulaziz University (KAU) hospital at $34^{+0}$ to $36^{+6}$ weeks gestation between June 15t, 2014 and March 30 th, 2015. Controls were mothers who delivered at term (37 or more gestation). Controls were matched 1:1 to cases by delivery date (within 2 days). Only women whose pregnancy was established by ultrasound in the first or early second trimester were included. Infants with major congenital anomalies were excluded from the study. King Abdulaziz University Hospital Conjoint Research Ethics Board reviewed and approved the study.

\section{Maternal Factors}

The effect of the following maternal factors on the incidence of late preterm birth was explored: maternal age, educational background (number of years), parity, history of previous preterm delivery, invasive procedures during pregnancy (chorionic villous sampling and amniocentesis), prenatal care status, body mass index (BMI), maternal smoking, diabetes ${ }^{[15]}$, hypertension (HTN), vaginal and urine culture during the third trimester, the use of ART, PROM and mode of delivery.

The total number of prenatal visits defined prenatal care ${ }^{[20]}$. Body mass index is estimated from information on height and weight at the first prenatal visit. Maternal smoking habits during pregnancy included both cigarette and/or sheisha smoking during pregnancy. Diabetes in pregnancy was either pre-gestational or gestational diabetes diagnosed according to the World Health Organization's diagnostic criteria for gestational diabetes ${ }^{[21]}$. Maternal hypertension is defined by the Committee on Terminology of American College of Obstetrics and Gynecology ${ }^{[22]}$ and included both chronic hypertension foregoing pregnancy and pregnancy-induced hypertension. Leakage of amniotic fluid before 37 weeks of gestational age was used to define preterm premature rupture of the membranes ${ }^{[23]}$.

Neonatal outcomes included neonatal mortality prior to discharge from hospital, condition at birth (cord arterial pH, Apgar scores at one and five minutes and the need for resuscitation), respiratory adverse outcomes comprising respiratory distress syndrome, transient tachypnea of neonate, apnea of prematurity and persistent pulmonary hypertension, hypothermia, hypoglycemia, hyperbilirubinemia, sepsis, feeding difficulty and duration of hospital stay. Respiratory distress is defined by a constellation of clinical signs and symptoms that persist more than two hours ${ }^{[24]}$. Persistent pulmonary hypertension is defined by echocardiographic finding of right to left or bidirectional shunting at foramen ovale or ductus arteriosus and/ or tricuspid regurgitation. Hypothermia is defined as temperature $<36.5^{\circ} \mathrm{C}$ that is persistent after standard warming measures. Hypoglycemia is defined as twoblood glucose less than $2.6^{[25]}$. Hyperbilirubinemia is defined as serum bilirubin level requiring phototherapy at any time during the neonatal period. Sepsis is defined as positive blood and /or central nervous system culture during hospital stay. Feeding difficulty is defined as feeding duration more than 30 minutes, difficulty waking the infant for feeding or fussiness, distress, breathing difficulty, lethargy, frequent coughs and chokes and decreased arousal during feeding ${ }^{[26]}$. We also studied the rate of readmission to the hospital and the reason for readmission by reviewing the charts of the discharged infants and calling the families 2 months after discharge to inquire about readmission in another hospital.

\section{Sample Size Calculation}

Since we studied multiple risk factors we calculated our sample size based on neonatal admission rate to the neonatal intensive care unit (NICU). For a 30\% admission rate of preterm infants to $\mathrm{NICU}^{[27]}$ and $6.3 \%$ for term infants ${ }^{[28]}$, at $5 \%$ level of significance and $80 \%$ power, a total sample size of 96 neonates was required, 48 in each group. A $10 \%$ increase in the sample size was 
entertained to account for attrition and missing data and that resulted in a total sample size of 106 neonates.

\section{Statistical Analysis}

IBM SPSS Statistics for Windows, Version 20 (IBM Corp., Armonk, NY USA) was utilized for all statistical tests. For descriptive statistics, $t$-test and chi-square or Fisher's exact test were employed to compare continuous and categorical variables correspondingly. Statistical significance was set at $5 \%$ level.

\section{Results}

A total of 106 infants were included, 53 infants in each group. Table 1 depicts maternal demographic and clinical features. Mothers of late preterm infants were older, had higher parity, BMI and increased number of multiple pregnancies. They did not vary from mothers of term infants in educational background, working status and smoking. Mothers in both groups had comparable number of antenatal visits and number of invasive procedures during pregnancy. Mothers in the late preterm group had increased use of antenatal steroid and cesarean delivery. Cesarean section $(C / S)$ for unknown reason or electively was the mode of delivery in more than two third of late preterm infants (75.7\%) compared to $57 \%$ of term infants (Table 2). Mothers of late preterm infants had significantly higher frequency of hypertension and PROM. More mothers in the late preterm infants group had encountered preterm labor and conceived using assisted reproductive technology, that did not reach statistical significance. Table 3 outlines infants' characteristics and rate of morbidities in both groups. Late preterm infants had significantly lower birth weight, needed more resuscitation, and

Table 1. Maternal characteristics.

\begin{tabular}{|c|c|c|c|}
\hline & $\begin{array}{c}\text { Cases } \\
\mathrm{N}=53\end{array}$ & $\begin{array}{c}\text { Controls } \\
\mathrm{N}=53\end{array}$ & p value \\
\hline \multicolumn{4}{|l|}{ Maternal Characteristics } \\
\hline Age & $33.0(5.9)$ & $30.6(5.7)$ & 0.03 \\
\hline Body Mass Index & $30.1(9.5)$ & $26.2(5.4)$ & 0.01 \\
\hline Parity & $3(0,6)$ & $2(0,9)$ & 0.04 \\
\hline Educational Background (number of years) & $16(6,20)$ & $16(6,21)$ & NS \\
\hline Working Mother & $22(41.5)$ & $15(28.3 \%)$ & NS \\
\hline No. of Antenatal Visits & $6(2,15)$ & $6(2,18)$ & NS \\
\hline Invasive Procedures during Pregnancy & $0(0.00 \%)$ & $3(5.67 \%)$ & NS \\
\hline Multiple Pregnancy & $16(30.19 \%)$ & $1(1.89 \%)$ & $<0.001$ \\
\hline Smoking & $4(7.54 \%)$ & $0(0.00 \%)$ & NS \\
\hline Previous History of Preterm Birth & $13(24.52 \%)$ & $6(11.32 \%)$ & NS \\
\hline Antenatal Steroids & $18(33.96 \%)$ & $2(3.77 \%)$ & $<0.001$ \\
\hline Cesarean Section & $37(69.81 \%)$ & $21(39.62 \%)$ & 0.002 \\
\hline Induction of Labor & $8(15.09 \%)$ & $13(24.52 \%)$ & NS \\
\hline Diabetes mellitus & $10(18.87 \%)$ & $7(13.21 \%)$ & NS \\
\hline Hypertension & $16(30.19 \%)$ & $5(9.43 \%)$ & 0.01 \\
\hline Premature Rupture of Membrane & $18(33.96 \%)$ & $1(1.89 \%)$ & $<0.001$ \\
\hline Positive Vaginal/Urine Culture & $5(9.43 \%)$ & $6(11.32 \%)$ & NS \\
\hline Assisted Reproductive Technology & $7(13.21 \%)$ & $1(1.89 \%)$ & NS \\
\hline
\end{tabular}

Results are expressed as: mean \pm SD, median, range or \%.

Table 2. Reason for cesarean delivery.

\begin{tabular}{|l|c|c|}
\hline \multicolumn{1}{|c|}{ Reason for Cesarean Section } & $\begin{array}{c}\text { C/S in Cases } \\
\mathbf{N = 3 7}\end{array}$ & $\begin{array}{c}\text { C/S in Controls } \\
\mathbf{N = 2 1}\end{array}$ \\
\hline Oligohydramnios & $0(0.00 \%)$ & $1(4.76 \%)$ \\
\hline Chorioamnionitis & $1(2.70 \%)$ & $0(0.00 \%)$ \\
\hline Hypertension/Eclampsia & $1(2.70 \%)$ & $1(4.76 \%)$ \\
\hline Previous Cesarean Section & $4(10.81 \%)$ & $5(23.81 \%)$ \\
\hline Placenta Previa & $1(2.70 \%)$ & $0(0.00 \%)$ \\
\hline Position of Baby & $2(5.40 \%)$ & $2(9.52 \%)$ \\
\hline Unknown/Elective & $28(75.68 \%)$ & $12(57.14 \%)$ \\
\hline Abbr: C/S: Cesarean section. & &
\end{tabular}


Table 3. Infant characteristics and rate of comorbidities.

\begin{tabular}{|c|c|c|c|}
\hline & $\begin{array}{l}\text { Cases } \\
\mathrm{N}=53\end{array}$ & $\begin{array}{c}\text { Controls } \\
\mathrm{N}=53\end{array}$ & $\mathrm{p}$ value \\
\hline \multicolumn{4}{|l|}{ Infant Characteristics } \\
\hline Birth weight $(\mathrm{g})$ & $229.6(37.6)$ & $323.3(37.61)$ & $<0.001$ \\
\hline Gestational age (weeks) & $35.2(0.85)$ & $38.9(0.92)$ & $<0.001$ \\
\hline Apgar score 1 minute & $8(3,9)$ & $9(1,9)$ & 0.03 \\
\hline Apgar score 5 minute & $10(6,10)$ & $10(6,10)$ & 0.007 \\
\hline \multicolumn{4}{|l|}{ Neonatal Morbidities } \\
\hline Need for resuscitation & $8(15.09 \%)$ & $2(3.77 \%)$ & 0.046 \\
\hline NICU Admission & $17(32.08 \%)$ & $1(1.89 \%)$ & $<0.001$ \\
\hline Respiratory Distress Syndrome & $8(15.09 \%)$ & $0(0.00 \%)$ & 0.006 \\
\hline Transient Tachypnea Of Neonate & $4(7.54 \%)$ & $0(0.00 \%)$ & NS \\
\hline Apnea of Prematurity & $1(1.89 \%)$ & $0(0.00 \%)$ & NS \\
\hline Need for Intubation & $2(3.77 \%)$ & $1(1.89 \%)$ & NS \\
\hline Continuous Positive Airway Pressure & $8(15.09 \%)$ & $0(0.00 \%)$ & 0.006 \\
\hline Hypoglycemia & $1(1.89 \%)$ & $1(1.89 \%)$ & NS \\
\hline Hyperbilirubinemia & $1(1.89 \%)$ & $0(0.00 \%)$ & NS \\
\hline Sepsis & $0(0 \%)$ & $1(1.89 \%)$ & NS \\
\hline Hospital Stay (days) & $4.4(3.7)$ & $2.4(2.1)$ & 0.001 \\
\hline Readmission & $3 / 50(6.00 \%)$ & $1 / 46(2.17 \%)$ & NS \\
\hline
\end{tabular}

Abbreviations: NICU, neonatal intensive care unit; Results are expressed as: mean \pm SD or median, range or \%.

exhibited lower one and five minutes Apgar scores compared to term infants. Significantly higher number of late preterm infants were admitted to the NICU, had respiratory distress syndrome (RDS), and needed to be supported with continuous positive airway pressure (CPAP). Moreover, late preterm infants exhibited significantly longer length of hospital stay than term infants. We did not discern a significant increase in the rate of other morbidities including hyperbilirubinemia, hypoglycemia, hypothermia, sepsis and feeding difficulty. Three infants in the late preterm group and one in the control group needed to be readmitted during the first month after discharge. Hyperbilirubinemia was the cause in two of the late preterm infants and sepsis was the cause of readmission in one infant of both groups.

\section{DISCUSSION}

The maternal factors associated with late preterm delivery identified in our study were comparable to other studies ${ }^{[29,30]}$. Compared to term infants, mothers of late preterm infants were older and had higher BMI, parity and multiple pregnancies. Hypertension and PROM are proven contributors to late preterm delivery. The study did not have the power to detect disparities in secondary outcomes and that can explain the statistically insignificant difference between the two groups in the rate of use of ART. A number of published studies have documented the association between ART and the increased risk of premature delivery and multifetal pregnancies ${ }^{[31,32]}$. A greater proportion of late preterm in neonates in our population was born by $\mathrm{C} / \mathrm{S}$ compared to term infants. Moreover, the motive for the greater number of $C / S$ in late preterm infants was either elective or unknown medical indication. Recent published data suggest that the increasing use of elective cesarean delivery has influenced the upsurge in rate of late preterm birth $^{[3,34]}$. $6-23 \%$ of late preterm deliveries resulting from elective or non-medically indicated deliveries could be potentially avoided ${ }^{[10,11]}$.

Respiratorymorbidities hadaccounted significantly to NICU admissions as shown in other studies ${ }^{[14,35]}$. Although several studies demonstrated that late preterm infants had increased risk of hypoglycemia, sepsis, hyperbilirubinemia requiring phototherapy and feeding difficulties compared to their term infants' counterparts, we failed to show similar findings in our study most likely because of the limited sample size to address all neonatal morbidities ${ }^{[36,37]}$. Several articles have evaluated the hospital readmission rate of late preterm infants in the neonatal period. In a population based cohort study by Tomashek et al. ${ }^{[38]}$, the admission rate for late preterm infants was reported to be 1.8 times higher than term infants in the first month after discharge. More recently, Kuzniewicz et al. ${ }^{[39]}$ reported similar conclusions of increasing the likelihood of 
readmission for late preterm infants compared with their matched term infants (RR 1.29; 95\% Cl, 1.13-1.47). The most common reasons for readmission included feeding problems, sepsis and hyperbilirubinemia ${ }^{[8,40]}$. We did not examine the neonatal cost relative to gestational age. Several studies have indicated that the overall average cost decreases with increasing gestational age at birth ${ }^{[30,41,42]}$. Moreover, we did not investigate maternal emotional impact of having a late preterm infant. Several published studies demonstrated that mothers of late preterm infants have greater emotional stress ${ }^{[43]}$ and symptoms of depression and anxiety compared to mothers of full term infants ${ }^{[44]}$.

Late preterm infants exhibit immaturity both developmentally and physiologically and endure more health co-morbidities than infants born at term. Recognizing maternal characteristics associated with late-preterm birth is important to help in implementing pre-pregnancy and prenatal care strategies aiming at modifying and reducing those factors. Furthermore, realizing mortality and morbidity risks among latepreterm infants is essential for supporting neonatal health care providers to develop guidelines and management plans adapted to the special requisites of late-preterm infants and to foresee conceivable morbidities that will prolong their hospital stay or bring them back to hospital after discharge. Further, for nonemergency obstetric decisions of late preterm birth, obstetricians ought to evaluate the potential increased maternal and perinatal morbidities of expectant management versus iatrogenic prematurity. Future studies should consider evaluating the effectiveness of methods to postpone late preterm deliveries and the impact of that on the reduction of neonatal adverse outcomes.

\section{Acknowledgement}

We thank Dr. Hanan Bajunaid, Dr. Reem Al-Wassia and Ms. Rola Al-Malki for their contribution to data collection for this study. Dr. Heidi Al-Wassia had full access to all of the data in the study and takes responsibility for the integrity of the data and the accuracy of the data analysis.

\section{Conflict of Interest}

The author has no conflict of interest.

\section{Disclosure}

The author did not received any type of commercial support either in forms of compensation or financial for this study. The author has no financial interest in any of the products or devices, or drugs mentioned in this article.

\section{Ethical Approval}

Obtained.

\section{References}

[1] Cheong JL, Doyle LW. Increasing rates of prematurity and epidemiology of late preterm birth. J Paediatr Child Health 2012; 48(9): 784-788.

[2] Martin JA, Kirmeyer S, Osterman M, Shepherd RA. Born a bit too early: recent trends in late preterm births. NCHS Data Brief 2009; (24): 1-8.

[3] Langhoff-Roos J, Kesmodel U, Jacobsson B, Rasmussen S, Vogel I. Spontaneous preterm delivery in primiparous women at low risk in Denmark: population based study. BMJ 2006; 332(7547): 937-939.

[4] Loftin RW, Habli M, Snyder CC, Cormier CM, Lewis DF, Defranco EA. Late preterm birth. Rev Obstet Gynecol 2010; 3(1): 10-19.

[5] Tomashek KM, Shapiro-Mendoza CK, Davidoff MJ, Petrini $J R$. Differences in mortality between late-preterm and term singleton infants in the United States, 1995-2002. J Pediatr 2007; 151(5): 450-456.

[6] Shapiro-Mendoza CK, Tomashek KM, Kotelchuck M, Barfield W, Weiss J, Evans S. Risk factors for neonatal morbidity and mortality among "healthy," late preterm newborns. Semin Perinatol 2006; 30(2): 54-60.

[7] Ortigosa Rocha C, Bittar RE, Zugaib M. Neonatal outcomes of late-preterm birth associated or not with intrauterine growth restriction. Obstet Gynecol Int 2010; 2010: 231842.

[8] McLaurin KK, Hall CB, Jackson EA, Owens OV, Mahadevia PJ. Persistence of morbidity and cost differences between late-preterm and term infants during the first year of life. Pediatrics 2009; 123(2): 653-659.

[9] Jefferies AL, Lyons ER, Shah PS, Shah V. Impact of late preterm birth on neonatal intensive care resources in a tertiary perinatal center. Am J Perinatol 2013; 30(7): 573578.

[10] Holland MG, Refuerzo JS, Ramin SM, Saade GR, Blackwell SC. Late preterm birth: how often is it avoidable? Am J Obstet Gynecol 2009; 201(4): 404.e1-4.

[11] Reddy UM, Ko CW, RajuTN, Willinger M. Delivery indications at late-preterm gestations and infant mortality rates in the United States. Pediatrics 2009; 124(1): 234-240.

[12] Aliaga S, Price W, McCaffrey M, Ivester T, Boggess K, TollesonRinehart S. Practice variation in late-preterm deliveries: a physician survey. J Perinatol 2013; 33(5): 347-351.

[13] Mandruzzato GP, Cali G, Chiaffarino F, Dal Pozzo G, Danti L, Gerosa V, lacobelli P, Laezza C, Macagno F, Parazzini, F, Scollo 
P. Risk factors for late preterm births: a case-control study. Gynecol Obstet 2013; 3: 182.

[14] Carter MF, Fowler S, Holden A, Xenakis E, Dudley D. The late preterm birth rate and its association with comorbidities in a population-based study. Am J Perinatol 2011; 28(9): 703707.

[15] Lee YM, Cleary-Goldman J, D'Alton ME. Multiple gestations and late preterm (near-term) deliveries. Semin Perinatol 2006; 30(2): 103-112.

[16] Helmerhorst FM, Perquin DA, Donker D, Keirse MJ. Perinatal outcome of singletons and twins after assisted conception: a systematic review of controlled studies. BMJ 2004; 328(7434): 261

[17] Laughon SK, Reddy UM, Sun L, Zhang J. Precursors for late preterm birth in singleton gestations. Obstet Gynecol 2010; 116(5): 1047-1055

[18] Mandal D, Manda S, Rakshi A, Dey RP, Biswas SC, Banerjee A. Maternal obesity and pregnancy outcome: a prospective analysis. J Assoc Physicians India 2011; 59: 486-489.

[19] Page RL, 2nd, Slejko JF, Libby AM. A citywide smoking ban reduced maternal smoking and risk for preterm births: a Colorado natural experiment. J Womens Health (Larchmt) 2012; 21(6): 621-627.

[20] Showstack JA, Budetti PP, Minkler D. Factors associated with birthweight: an exploration of the roles of prenatal care and length of gestation. Am J Public Health 1984; 74(9): 1003-1008.

[21] [No authors listed]. Diagnostic criteria and classification of hyperglycemia first detected in pregnancy. Geneva, World Health Organization 2013, 63.

[22] ACOG Committee on Practice Bulletins. ACOG Practice Bulletin. Chronic hypertension in pregnancy. ACOG Committee on Practice Bulletins. Obstet Gynecol 2001; 98(1): suppl 177-185

[23] [No authors listed]. Practice bulletins No. 139: premature rupture of membranes. Obstet Gynecol 2013; 122(4): 918930.

[24] Adamkin DH. Feeding problems in the late preterm infant. Clin Perinatol 2006; 33(4): 831-837.

[25] Lucas A, Morley R, Cole TJ. Adverse neurodevelopmental outcome of moderate neonatal hypoglycaemia. BMJ 1988; 297(6659): 1304-1308.

[26] Dave VA, Campbell DE. Care of the Late Preterm Infant. In: AAP Textbook of Pediatric Care. Mclnerny TK, Adam HM, Campbell DE, Kamat DM, Kelleher KJ, Hoekelman RA, eds. American Academy of Pediatrics; 2009.

[27] Celik IH, Demirel G, Canpolat FE, Dilmen U. A common problem for neonatal intensive care units: late preterm infants, a prospective study with term controls in a large perinatal center. J Matern Fetal Neonatal Med 2013; 26(5): 459-462.

[28] Tracy SK, Tracy MB, Sullivan E. Admission of term infants to neonatal intensive care: a population-based study. Birth 2007; 34(4): 301-307.
[29] Engle WA. Morbidity and mortality in late preterm and early term newborns: a continuum. Clin Perinatol 2011; 38(3): 493-516.

[30] Elliott JP, Istwan NB, Jacques DL, Coleman SK, Stanziano GJ. Consequences of nonindicated preterm delivery in singleton gestations. J Reprod Med 2003; 48(9): 713-717.

[31] Reddy UM, Wapner RJ, Rebar RW, Tasca RJ. Infertility, assisted reproductive technology, and adverse pregnancy outcomes: executive summary of a National Institute of Child Health and Human Development workshop. Obstet Gynecol 2007; 109(4): 967-977.

[32] Sunderam S, Chang J, Flowers L, Kulkarni A, Sentelle G, Jeng G, Macaluso M; Centers for Disease Control and Prevention (CDC). Assisted reproductive technology surveillance-United States, 2006. MMWR Surveill Summ 2009; 58(5): 1-25.

[33] Fuchs K, Wapner R. Elective cesarean section and induction and their impact on late preterm births. Clin Perinatol 2006; 33(4): 793-801.

[34] Bettegowda VR, Dias T, Davidoff MJ, Damus K, Callaghan WM, Petrini JR. The relationship between cesarean delivery and gestational age among US singleton births. Clin Perinatol 2008; 35(2): 309-323.

[35] McIntire DD, Leveno KJ. Neonatal mortality and morbidity rates in late preterm births compared with births at term. Obstet Gynecol 2008; 111(1): 35-41.

[36] Wang ML, Dorer DJ, Fleming MP, Catlin EA. Clinical outcomes of near-term infants. Pediatrics 2004; 114(2): 372-376.

[37] Melamed N, Klinger G, Tenenbaum-Gavish K, Herscovici T, Linder N, Hod M, Yogev Y. Short-term neonatal outcome in low-risk, spontaneous, singleton, late preterm deliveries. Obstet Gynecol 2009; 114(2 Pt 1): 253-260.

[38] Tomashek KM, Shapiro-Mendoza CK, Weiss J, Kotelchuck M, Barfield W, Evans S, Naninni A, Declercq E. Early discharge among late preterm and term newborns and risk of neonatal morbidity. Semin Perinatol 2006; 30(2): 61-68.

[39] Kuzniewicz MW, Parker SJ, Schnake-Mahl A, Escobar GJ. Hospital readmissions and emergency department visits in moderate preterm, late preterm, and early term infants. Clin Perinatol 2013; 40(4): 753-775.

[40] Jain S, Cheng J. Emergency department visits and rehospitalizations in late preterm infants. Clin Perinatol 2006; 33(4): 935-945

[41] GilbertWM, NesbittTS, Danielsen B. The cost of prematurity: quantification by gestational age and birth weight. Obstet Gynecol 2003; 102(3): 488-492.

[42] St John EB, Nelson KG, Cliver SP, Bishnoi RR, Goldenberg RL. Cost of neonatal care according to gestational age at birth and survival status. Am J Obstet Gynecol 2000; 182(1 Pt 1): 170-175.

[43] Brandon DH, Tully KP, Silva SG, Malcolm WF, Murtha AP, Turner BS, Holditch-Davis D. Emotional responses of 
mothers of late-preterm and term infants. J Obstet Gynecol Neonatal Nurs 2011;40(6): 719-731.

[44] Voegtline KM, Stifter CA; Family Life Project Investigators. Late-preterm birth, maternal symptomatology, and infant negativity. Infant Behav Dev 2010; 33(4): 545-554. 


\title{
العوامل الوالدية (الأمهات ) و الوفيات والأمراض في حديثي الولادة المرتبطة بولادة الخدج المتأخرة
}

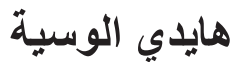

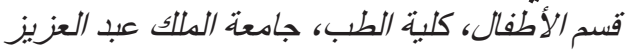

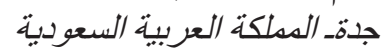

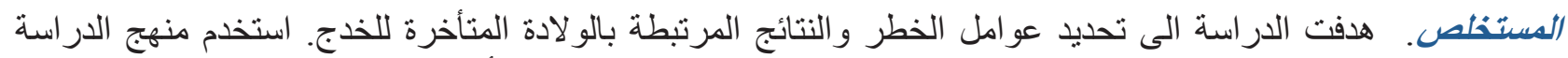

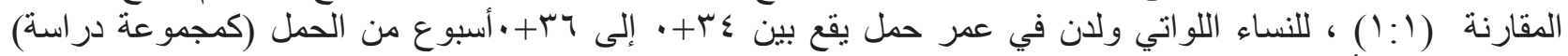

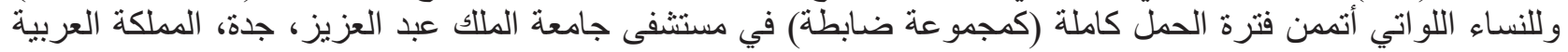

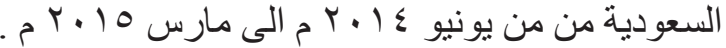

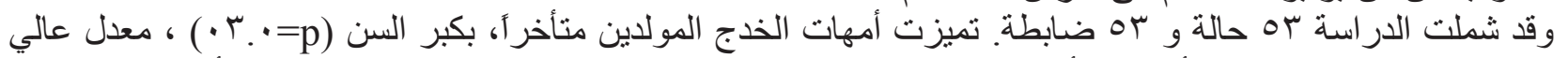

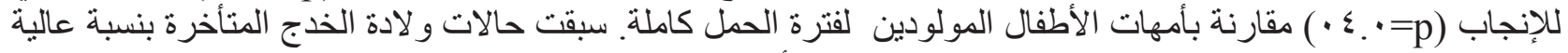

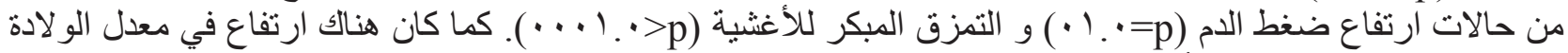

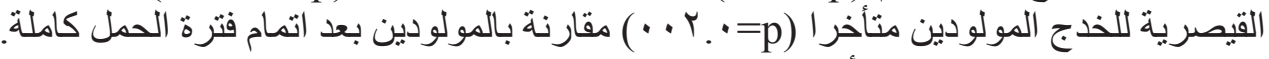

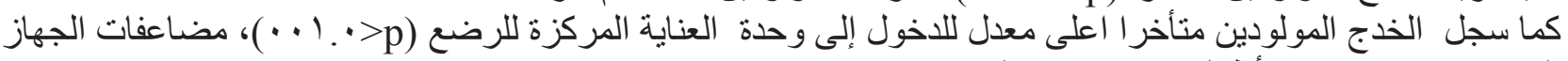

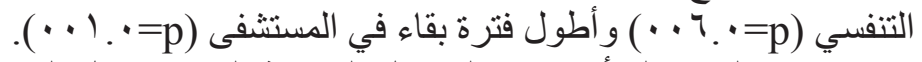

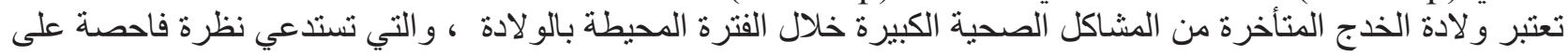

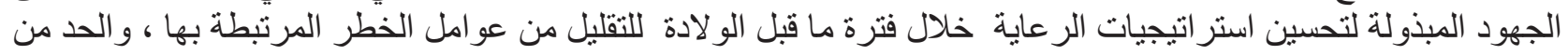

الو لادات المبكرة غير المقررة طبيا. 